\title{
Signs of progress in the Australian post-2000 COPD experience, but some old problems remain
}

This article was published in the following Dove Press journal:

International Journal of COPD

6 June 2012

Number of times this article has been viewed

\author{
David Dunt ${ }^{1}$ \\ Colleen Doyle ${ }^{1,2}$ \\ 'Centre for Health Policy, Programs \\ and Economics, Melbourne School \\ of Population Health, The University \\ of Melbourne, Parkville, Victoria, \\ Australia; ${ }^{2}$ National Ageing Research \\ Institute, Royal Melbourne Hospital, \\ Victoria, Australia
}

\begin{abstract}
This study aims to describe current trends in Australia regarding chronic obstructive pulmonary disease (COPD) mortality and morbidity rates, and in its treatment and prevention from 2000 to 2010. The study's purpose is to better define future directions in curbing COPD. People with COPD and their caregivers who attend patient support groups $(n=21)$, pulmonary rehabilitation group coordinators $(n=27)$ within Victoria, and the Australian Lung Foundation provided informed feedback. COPD was a leading underlying cause of death in both sexes during these years. Nevertheless, mortality rates declined from 1980 to 2007, with rates for males almost halving. Its prevalence has also substantially declined. Smoking rates have declined in age groups over 40 years old in both sexes. The COPD-X Plan provides evidence-based guidelines for the management of COPD. Many government, professional, and community initiatives have been recently implemented to promote the Plan. Two studies - one conducted before and one conducted after the publication of the COPD-X Plan - report some progress, but there are still very considerable departures from evidence-based practice. The Australian Lung Foundation estimates that only $1 \%$ of patients who could benefit from pulmonary rehabilitation programs have suitable access to such programs. A common priority for all informants was that there needed to be greater awareness of - and a more positive orientation to - COPD in both the Australian and health professional communities. The study concluded that substantial reductions in COPD and smoking cessation rates contrast with more limited progress toward adopting other aspects of evidence-based practice. The "good news" story concerning reductions in COPD disease with improving smoking cessation rates could form the basis for suitable media campaigns.
\end{abstract}

Keywords: COPD, disease trends, community perceptions, health services planning

\section{Introduction}

Chronic obstructive pulmonary disease (COPD) is a chronic progressive disease that, from the patient's point of view, is most unpleasant. Assessed by any measure, such as mortality, morbidity, disability, overall burden of disease, or health care costs, it is a significant cause of poor community health. It is predicted to become the third-leading cause of death by 2020 worldwide. ${ }^{1}$ Nevertheless, it is underdiagnosed and awareness of its impact is low. There has been much activity by governments and health care professionals, through their contribution to the Global Initiative for Chronic Obstructive Lung Disease (GOLD), to improve this situation. ${ }^{2}$ This includes the development of evidence-based guidelines that demonstrate that prevention and treatment for the disease can be effective. Nevertheless, nihilism about the condition and its treatment is widespread. ${ }^{3}$

\author{
Correspondence: David Dunt \\ and Economics, Melbourne School \\ of Population Health, The University \\ of Melbourne, VIC 30I0, Australia \\ Tel +6I 383872305 \\ Fax +6I 393874030 \\ Email d.dunt@unimelb.edu.au
}


This article consists of two parts. Part A examines some recently published research on COPD in Australia concerning current levels, risk factors, and the nature of COPD management in Australia. Part B reports informants' perspectives about COPD in Australia, particularly in relation to programs needed to improve community and professional interest in and attitudes toward the disease, as well as to improve service delivery.

The aim of assembling these different pieces of evidence is to provide a snapshot of the disease in Australia over the last decade (2000-2010) and, where possible, to examine current trends in COPD mortality and morbidity, as well as its prevention and treatment. The purpose of such action is to elucidate to what extent there has been progress or otherwise in the reduction of COPD levels as a result of improvements in services and programs in one medium-size developed country. We interpret these findings and their significance in pointing to future directions that will best curb COPD.

\section{Part A: Recently published research relevant to COPD in Australia Mortality, morbidity, and burden of disease of COPD in Australia}

COPD is a significant cause of death in Australia, being recorded in 2007 as the underlying cause of 5152 deaths (4\% of all deaths) and an associated cause in another 7336 deaths. ${ }^{4}$ The mortality rate (underlying cause) is 31 per 100,000 for males and 16 per 100,000 for females. Based on these rates, COPD was the fourth-leading underlying cause of death for males and sixth for females in Australia in 2007. ${ }^{5}$ COPD is also a significant contributor $(3.0 \%)$ to the total burden of disease and injury, a number equally shared by males and females.

The 2003 Survey of Disability, Ageing and Carers estimated that approximately $34 \%$ of those reporting emphysema and bronchitis (as described) have some degree of disability, with $12 \%$ having severe or profound disability. ${ }^{6}$ Disability was twice as common in males as in females. The estimated direct expenditure associated with COPD for 2004-2005 was A $\$ 548.7$ million, $61 \%$ of which was for hospitalizations. ${ }^{4}$ In 2007-2008, there were 59,427 hospitalizations ( $1 \%$ of all hospitalizations) for COPD as the principal diagnosis in Australia. The average length of stay (6.9 days) was over twice the average of all hospital stays (3.3 days).

Based on self-reported information in the 20072008 National Health Survey, an estimated 490,000 Australians (2.3\% of the population) had emphysema or bronchitis (as described). ${ }^{7}$ This is likely to be an underestimate, as people may not be aware they have COPD, particularly if they have the mild Stage 1 disease, or if they erroneously believe they have asthma.

In general, estimates of COPD prevalence differ according to the estimation method used, such as self-reporting and doctor diagnoses with or without spirometry. In an epidemiological survey, taken in 2000, that included lung function testing of adults aged 45-70 years from southeastern Melbourne, Matheson et al estimated that $3.5 \%$ of this population had Stage 2 or higher COPD based on the GOLD staging criteria, with an extra $3.6 \%$ of subjects having COPD (Stage 2 or 3 ) plus asthma. ${ }^{8}$ Only $10 \%$ to $15 \%$ of subjects with COPD and no other disease had been diagnosed with COPD.

In the Burden of Obstructive Lung Diseases (BOLD) international study of COPD prevalence, the prevalence of Stage 2 or higher COPD in adults 40 years and over in southeastern Sydney was reported as being $10.8 \% .^{9}$ This is slightly higher than the $10.1 \%$ across the study's 12 international sites. This obscures the fact that prevalence in males was in the top quartile, but prevalence in females was in the bottom quartile. An unpublished 2011 study by Toelle of COPD prevalence in BOLD sites across Australia confirmed this Melbourne-Sydney difference., ${ }^{910}$

One estimate of the number of cases of COPD in Australia, using both the National Health Survey and BOLD studies, was two million across all stages, and 1.2 million for Stage 2-4 COPD. ${ }^{11}$

In Victoria, hospital admission rates for COPD cases have remained significantly higher in rural areas compared to metropolitan areas. ${ }^{12}$ Multiple logistic regression analyses in this study also revealed that increasing hospital admission rates were associated with increased smoking rates within the area, as well as its remoteness and social disadvantages.

\section{Recent trends in mortality and morbidity in Australia}

Figure 1 shows that COPD mortality rates (underlying cause) halved from 1980 to $2007 .{ }^{4}$ Rate changes in males and females were very different: rates for males have almost halved, while rates for females have risen slightly. Despite this, from 1987 to 2006, Australia's COPD mortality ranking has fallen from the top to the middle-third band of participating Organization for Economic Cooperation and Development (OECD) countries. ${ }^{4}$

Based on successive national health surveys, the prevalence of emphysema and bronchitis (as described) declined from $4.1 \%$ in 1995 to $2.3 \%$ in $2007-2008$. 


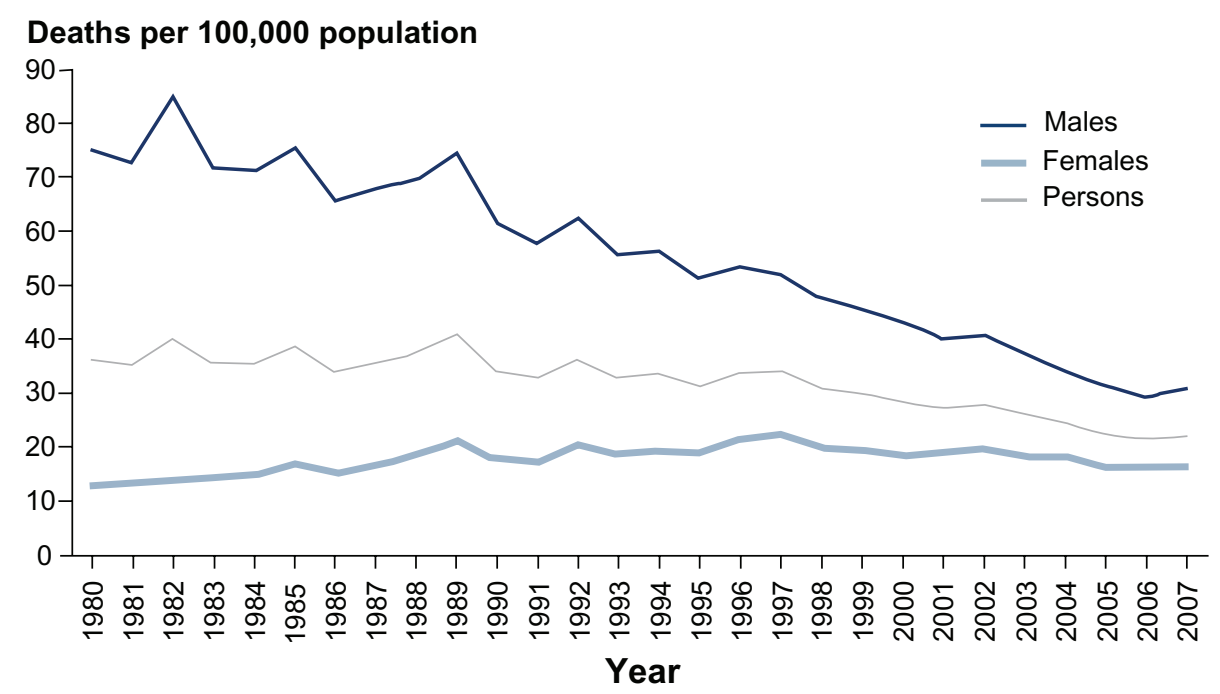

Figure I Trends in chronic obstructive pulmonary disease mortality, 1980 to 2007. Copyright $\odot$ 2010, AlHW. Reproduced with permission from AlHW. Australia's Health 2010. Australia's health series no. 12. Cat. no. AUS I22. Canberra, Australia: AlHW; $2010{ }^{4}$

COPD hospitalization rates have remained fairly stable from 1998-1999 to 2006-2007; male rates have declined somewhat, and female rates have increased slightly. ${ }^{13}$

\section{Trends in tobacco smoking rates in Australia}

These trends for COPD are better understood in the light of smoking rate trends. Smoking rates have declined in the age groups over 40 years old in Australia from 1980 to 2004 (Figure 2).${ }^{14}$ Rates in the 60 years and over age group have declined from $23 \%$ to $13 \%$ for males and from $16 \%$ to $9 \%$ for females. In the $40-59$ years old age group, rates declined from $44 \%$ to $24 \%$ for males and from $27 \%$ to $22 \%$ for females. Australia's ranking for smoking rates rose from the middle-third to the best-third band of OECD countries for the period 1987-2006. ${ }^{4}$ This decline is consistent with the objectives of Australia's National Tobacco Strategy, which aim to prevent the uptake of smoking across all social groups, to encourage and assist as many smokers as possible in quitting as soon as possible, to eliminate harmful exposure to tobacco smoke among nonsmokers and, where feasible, to reduce harm associated with the continuing use of and dependence on tobacco and nicotine. ${ }^{15}$

\section{Evidence-based guidelines for the management of COPD in Australia}

The 2001 GOLD workshop report constituted the original primary evidence base that led to the development of the

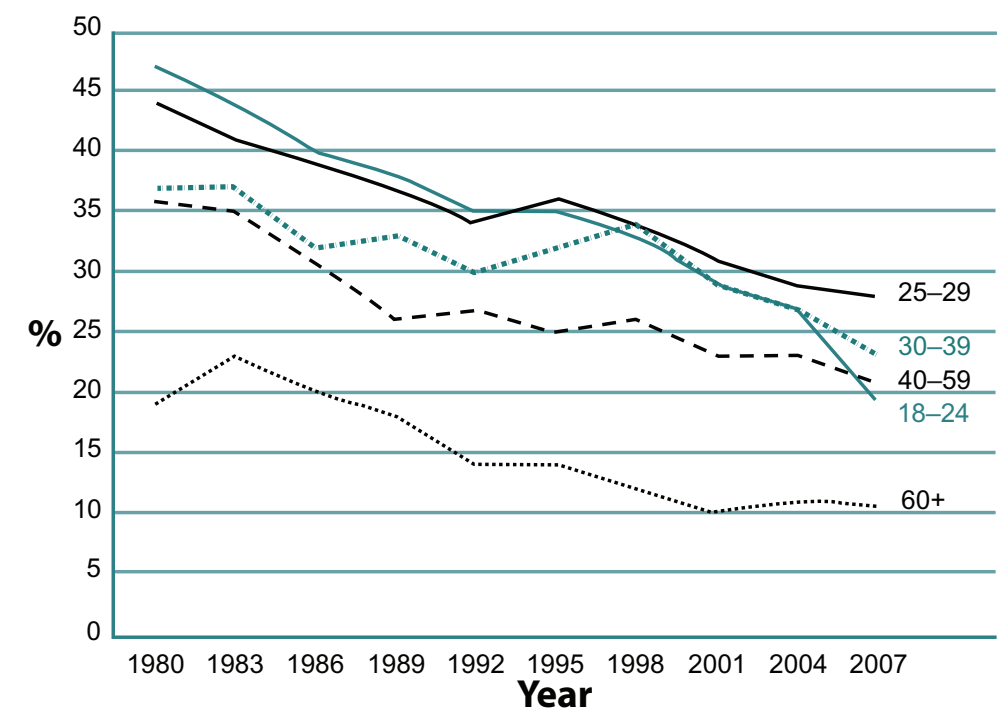

Figure 2 Prevalence of current smokers in Australia aged 18 years and over, 1980-2007. 
Australian and New Zealand guidelines for the management of COPD (the COPD-X Plan). ${ }^{16}$ This was a joint initiative of the Thoracic Society of Australia and New Zealand and the Australian Lung Foundation (ALF), and was first published in 2003. Subsequent modifications to the guidelines have been based on subsequent versions of the GOLD report and on the results of systematic reviews or well-conducted, randomized control trials. ${ }^{17}$

The COPD-X Plan 2010 is summarized in Table 1. Guidelines with very direct applications on patient care involve pulmonary rehabilitation (PR), treatment of nicotine dependence, and influenza vaccination. There are new insights in relation to pharmacological treatments and psychosocial supports.

\section{Government and nongovernment activities to improve COPD management}

A whole range of government, professional, and community initiatives have been put in place during the past 10-15 years to promote the take-up of evidence-based management for COPD, the most important of which are described below.

First, chronic disease strategies, which prominently include COPD, exist at both the Commonwealth and State levels. ${ }^{18}$ The most important include:

- Funding for governmental programs of self-management and care coordination, such as the Chronic Disease Framework (the Australian Better Health Initiative and the Australian Primary Care Collaboratives Program) ${ }^{19}$ and

- Special funding arrangements (the Chronic Disease Management [CDM] Medicare Items and Spirometry Items) under Medicare Australia, the universal health insurance scheme that reimburses patients for medical costs. $^{20}$

Moreover, active smoking quitlines exist in all States and Territories (such as Quit Victoria). ${ }^{21}$

ALF is active in supporting people with COPD. It has established, among other initiatives, a National Patient Support Group Network and a Lung Foundation website, staged a National Summit Conference to determine future research directions, and set up multidisciplinary consultative groups in major lung disease categories that include COPD. It publishes and promotes the COPD-X guidelines (see above), and lists on its Website approximately 160 PR programs for COPD and 120 patient support groups for people with lung conditions across the country.
Table I COPD-X guidelines 2010

C: confirm diagnosis and assess severity

- Smoking is the most important risk factor in the development of COPD

- Consider COPD in all smokers and exsmokers over the age of 35 years

- The A diagnosis of COPD rests on the demonstration of airflow limitation that is not fully reversible

- If airflow limitation is fully or substantially reversible (FEV, response to bronchodilator $>400 \mathrm{~mL}$ ), the patient should be treated as for asthma

- Consider COPD in patients with other smoking-related diseases

O: optimize function

- Inhaled bronchodilators provide symptom relief and may increase exercise capacity

- Long-term use of systemic glucocorticoids is not recommended

- Inhaled glucocorticoids should be considered in patients with moderate to severe COPD and frequent exacerbations

- Pulmonary rehabilitation reduces dyspnea, fatigue, anxiety, and depression; improves exercise capacity, emotional function, and health-related quality of life; and enhances patients' sense of control over their condition

- Pulmonary rehabilitation reduces hospitalization and has been shown to be cost-effective

- Prevent or treat osteoporosis

- Identify and treat hypoxemia and pulmonary hypertension

- In selected patients, a surgical approach may be considered for symptom relief

P: prevent deterioration

- Smoking cessation reduces the rate of lung function decline

- Treatment of nicotine dependence is effective and should be offered to smokers in addition to counseling

- Influenza vaccination reduces the risk of exacerbations, hospitalization, and death

- Mucolytics may reduce the frequency and duration of exacerbations

- Long-term oxygen therapy ( $>15$ hours/day) prolongs life in hypoxemic patients $\left(\mathrm{PaO}_{2}<55 \mathrm{mmHg}\right.$ or $\left.7.3 \mathrm{kPa}\right)$

D: develop support networks and self-management

- COPD imposes handicaps that affect both patients and carers

- Enhancing quality of life and reducing handicap requires a support team

- Patients and their family/friends should be actively involved in a therapeutic partnership with a range of health professionals

- Multidisciplinary care plans and individual self-management plans may help to prevent or manage crises

- Patients who take appropriate responsibility for their own management may have improved outcomes

- Anxious and depressive symptoms and disorders are common co-morbidities in people with COPD

\section{$X$ : manage eXacerbations}

- An exacerbation is an event in the natural course of the disease characterized by a change in the patient's baseline dyspnea, cough, and/or sputum that is beyond normal day-to-day variations, is acute in onset, and may warrant a change in regular medication in a patient with underlying COPD

- Early diagnosis and treatment may prevent admission

- Multidisciplinary care may assist home management

- Inhaled bronchodilators are effective treatments for acute exacerbations

Abbreviations: COPD, chronic obstructive pulmonary disease; $\mathrm{FEV}_{\mathrm{V}}$, forced expiratory volume in one second; $\mathrm{PaO}_{2}$, partial pressure of oxygen in the blood. 


\section{Conformity of clinical practice in Australia to the COPD-X Plan}

It is possible to some extent to judge how far clinical practice in Australia conforms to the COPD-X Plan, largely as a result of two studies, even though they involve very different patient populations. The first of these is the 2000 study by Matheson et al, which was conducted three years before the publication of the first COPD-X Plan. ${ }^{8}$ The second is the 2008 study by Ta and George, which was conducted five years after its publication. ${ }^{22}$ In contrast to Matheson et al's large, population-based study, ${ }^{8}$ Ta and George's study of 45 COPD patients was drawn from one hospital in which the patients had been admitted with acute COPD exacerbations. ${ }^{22}$ The group also had a large mean number of comorbidities (5.7), medications (10.4), and hospital admissions (3.1 in past 12 months).

The levels of conformity for parameters for both studies are set out in Table 2. With some caution due to differences in the two populations, these studies would seem to indicate increasing conformity with the COPD-X plan. Substantial departures from evidence-based practice clearly remain, however.

Other results from Matheson et al's study ${ }^{8}$ included:

- $38.5 \%$ of the COPD-only group had seen a general practitioner in the past 12 months;

- $48.7 \%$ of the COPD-only group and $75 \%$ of the COPD/ asthma group had been prescribed inhaled medication for their breathing in the previous 12 months, while $18.0 \%$ and $17.5 \%$, respectively, had been prescribed oral medication for their breathing in the previous 12 months; and

- $5.1 \%$ of the COPD-only group had been regularly using long-acting $\beta_{2}$ agonists during the past 12 months, while $23.1 \%$ and $30.0 \%$, respectively, had been regularly using inhaled steroids during the past 12 months.

Table 2 Conformity of clinical practice with the COPD-X Plan

\begin{tabular}{|c|c|c|}
\hline & $\begin{array}{l}\text { Matheson et al* } \\
\text { (conducted } \\
2000)\end{array}$ & $\begin{array}{l}\text { Ta and George* } \\
\text { (conducted } \\
2008 \text { ) }\end{array}$ \\
\hline $\begin{array}{l}\text { Diagnosis of COPD } \\
\text { provided by doctor }\end{array}$ & $10 \%$ & $87 \%$ \\
\hline Respiratory tests performed & $13 \%$ & $71 \%$ \\
\hline Specialist seen & $15 \%$ & $31 \%$ \\
\hline Influenza vaccination & $59 \%$ & $87 \%$ \\
\hline Pneumococcal vaccination & $41 \%$ & $69 \%$ \\
\hline Oxygen therapy & $3 \%$ & $13 \%$ \\
\hline Continued to smoke & $15 \%$ & $24 \%$ \\
\hline
\end{tabular}

Notes: *Results should be interpreted carefully given differences in patient populations and some differences in the wording of questions.

Abbreviation: COPD, chronic obstructive pulmonary disease.
Other results from Ta and George's study ${ }^{22}$ included:

- medications not supported by the COPD-X guidelines systematic steroids (24\%) and prophylactic antibiotics (7\%) - continued to be used long-term;

- $44.4 \%$ had started a pulmonary rehabilitation program, with $20 \%$ of participants completing a program;

- $24.4 \%$ had received medical instructions regarding the management of exacerbations; and

- $48.9 \%$ reported good adherence in taking all of their COPD medications (mean 3.4).

ALF has also estimated that only $1 \%$ of patients with COPD who can benefit from PR have access to such programs. ${ }^{23}$ An ALF-commissioned survey of PR coordinators indicated that the three main barriers to the operation of PR programs were patient transport, patient drop-out, and ongoing funding. ${ }^{24} \mathrm{~A}$ lack of awareness of PR programs by primary care providers was nominated as the most common barrier to access by those patients not currently using the programs that would benefit from them.

\section{Part B: Current stakeholder perceptions about needed developments in COPD services and programs}

The aim of Part B is to better understand ideas and insights about improving the prevention and care of COPD in Australia, both among people with the disease and their families, as well as relevant health professionals. These included:

- People with COPD and their caregivers attending patient support groups in Victoria;

- Coordinators of all PR groups in Victoria; and

- ALF, the peak body in Australia for relevant health care professionals with interest in pulmonary diseases, as well as people with these diseases and their families. A principal focus of ALF is people with COPD and their families.

\section{People with COPD and their caregivers Methods}

Submissions on problems and proposed solutions concerning COPD were sought from all 31 patient support groups in Victoria through the ALF newsletter. Questions were in two parts: first, how the government could improve awareness, prevention, detection, and treatment of COPD, and second, individual experiences of barriers to managing COPD and 
possible solutions. Twenty-one submissions were received: four on behalf of a particular patient support group, and 17 from individuals within a patient support group. This submission-based approach was preferred to the more usual survey method (whether by questionnaire or interview), as it aimed to collect opinions of informants with opinions about future service development, rather than typical sufferers of COPD. The main points of these submissions, together with some direct quotes of support group members making submissions, are set out below.

\section{Results}

A number of submissions included the comment that, while public awareness of asthma had increased as a result of mass media campaigns, public awareness of COPD remained very low. People believed that TV or radio awareness campaigns were the most effective ways of raising awareness, as these media communicate with a wide audience. Raising public awareness should include the meaning of the abbreviation $C O P D$ as, unlike asthma, it is not commonly understood.

A number of respondents commented that antismoking campaigns should be targeted at specific groups, such as older people or teenagers. Below are two representative comments:

Back to the public campaign. Show the difference between a healthy 65-year-old exercising, golf, tennis, swimming, cycling compared to a COPD sufferer ... hardly able to walk to the letter box, or leaning up against the shop window to try to get their breath.

Have more people of different age brackets appearing on the TV saying how they managed to quit.

A number of comments indicated that attitudes toward the disease needed to improve. Existing attitudes led to the disease being hidden, meaning that some people try to suffer in silence:

... because of the lack of knowledge and understanding, the person with COPD tries to cover up and not let on ... Most of the [people with COPD] I have met try to battle along on their own keeping quiet about their real condition.

A number of comments addressed the need for earlier detection of the disease. This required greater awareness by doctors and other health professionals, and highlights the need to investigate symptoms of shortness of breath and persistent cough by using lung function tests.

With regard to the treatment of COPD, some comments pointed to the importance of reduced costs for medications and more information about the use of portable oxygen and concentrators, both for patients and for general practitioners. They regarded mobility aids such as scooters, walking frames, and walking sticks as vital for this group of clients, as "Lack of mobility as the disease progresses is a huge barrier to managing COPD."

\section{Pulmonary rehabilitation coordinators \\ Methods}

Questionnaires were sent via email and mail to all 53 PR program coordinators in Victoria. The questionnaire included a list of 19 interventions proposed to improve the awareness, prevention, or treatment of the disease (see Table 1). These interventions were identified by reviewing the research literature on COPD. Coordinators were invited to rank these interventions in a priority order (highest $=1$; lowest $=6)$, and to provide additional comments in support of their rankings. Twenty-seven $(50 \%)$ of the PR coordinators responded.

\section{Results}

The mean levels for the respondents' rankings are set out in Table 3. The priorities of the PR coordinators, perhaps not unexpectedly, related to PR programs. They rated increased numbers and support for PR programs as the highest priority, and the investigation of reasons for low PR program use as their fifth-highest priority.

I think it is vital that these programs are promoted and money is given to them and they are not the responsibility of the health services, as there are always budget restrictions on health services and you can't get new equipment when it is needed.

The second-highest priority was more awareness campaigns aimed at the community and targeted at geographic locations where COPD was likely to present particular problems.

The next two highest priorities related to general practitioners - specifically the better use of spirometry and smoking cessation guidelines and awareness campaigns: "GPs need to be more aware of these programs and their benefits and thus referring to appropriate groups."

The next two highest priorities related to government first, to developing a government service framework for COPD to assist in the referral process, and second, to increasing support for ALF and its advocacy and awareness 
Table 3 Priority order among 19 potential interventions for PR coordinators $(N=26)$

\begin{tabular}{|c|c|c|}
\hline Intervention strategy & Priority order & $\begin{array}{l}\text { Mean rank } \\
(I=\text { high; } 6=\text { low })\end{array}$ \\
\hline $\begin{array}{l}\text { Increased numbers of pulmonary rehab programs and increased } \\
\text { support for existing pulmonary rehabilitation programs }\end{array}$ & Ist & 3.62 \\
\hline $\begin{array}{l}\text { Target awareness campaigns in key geographical areas with } \\
\text { high rates for of COPD, low rates of SES }\end{array}$ & 2nd & 4.81 \\
\hline $\begin{array}{l}\text { Encourage use of spirometry in screening by general } \\
\text { practitioners }\end{array}$ & Equal 3rd & 5.00 \\
\hline $\begin{array}{l}\text { Reinforce use of smoking cessation guidelines and awareness } \\
\text { campaigns by general practitioners }\end{array}$ & Equal 3rd & 5.00 \\
\hline Develop a government service framework for COPD & Equal 4th & 5.15 \\
\hline $\begin{array}{l}\text { Increase support for Australian Lung Foundation advocacy } \\
\text { and awareness activities }\end{array}$ & Equal 4th & 5.15 \\
\hline $\begin{array}{l}\text { Investigate reasons for low use of pulmonary rehabilitation programs; } \\
\text { identification of ideal ratio of programs to population }\end{array}$ & 5 th & 5.27 \\
\hline $\begin{array}{l}\text { Intervene to improve health professionals' attitudes toward } \\
\text { patients with COPD }\end{array}$ & 6th & 5.31 \\
\hline $\begin{array}{l}\text { Better information on prevalence of COPD at a regional } \\
\text { or local levels }\end{array}$ & 7th & 5.50 \\
\hline $\begin{array}{l}\text { Increase numbers and support for patient-support groups } \\
\text { for those with COPD }\end{array}$ & 8th & 6.12 \\
\hline Routine referral of smokers to quitlines by general practitioners & 9th & 6.15 \\
\hline $\begin{array}{l}\text { Target campaign to improve awareness of key at at-risk groups } \\
\text { such as Asian or Middle Eastern men }\end{array}$ & I0th & 6.19 \\
\hline $\begin{array}{l}\text { Identify key industries and groups of workers with high-risk } \\
\text { occupational exposure to dust and fumes }\end{array}$ & IIth & 6.27 \\
\hline $\begin{array}{l}\text { Increase awareness of dietary and weight risk factors for the } \\
\text { general public, those at risk, and those with COPD }\end{array}$ & Equal I2th & 6.31 \\
\hline $\begin{array}{l}\text { Monitor air pollution levels and raise awareness of air pollution } \\
\text { risk to lung function }\end{array}$ & Equal I2th & 6.31 \\
\hline $\begin{array}{l}\text { Increase advocacy and awareness activities of existing patient } \\
\text { support groups }\end{array}$ & 13th & 6.35 \\
\hline $\begin{array}{l}\text { Routine administration of influenza vaccinations } \\
\text { for smokers and those with COPD }\end{array}$ & 14th & 6.42 \\
\hline $\begin{array}{l}\text { Increased awareness of genetic susceptibility in families } \\
\text { with COPD history }\end{array}$ & 15 th & 6.58 \\
\hline $\begin{array}{l}\text { Increased awareness and promotion of World COPD Day } \\
\text { by local governments, primary care partnerships, }\end{array}$ & 16th & 6.73 \\
\hline
\end{tabular}

Abbreviations: COPD, chronic obstructive pulmonary disease; PR, pulmonary rehabilitation; SES, socioeconomic status.

activities. The next highest priority related to the need to improve other health professionals' attitudes toward patients with COPD.

I work in both an acute setting (ED) and chronic illness programme ... and am appalled by the apparent lack of awareness or concern of many of my fellow health professionals in regards to the severity of the problems associated with COPD. Before we can inform the general public the health profession needs to be targeted with some heavy duty awareness campaigns and education.

Along with other stakeholders, PR coordinators commented that a multifaceted approach was needed to address current shortcomings.

\section{Peak bodies}

Representatives of ALF were contacted regarding priorities for interventions to promote the prevention and management of COPD. Some other relevant bodies, such as the Australian Asthma and Respiratory Educators Association, were also contacted.

ALF is the peak body for COPD in Australia. Its longterm COPD strategy includes all three levels of prevention, as well as disease management. ${ }^{16}$ Some of its goals include:

- Primary prevention of smoking;

- Improving rates of smoking cessation;

- Early detection of airflow limitation in smokers before disablement;

- Improved management of stable diseases; and 
- Preventing exacerbations in people with established COPD.

It has produced a case statement for communicating with different key groups. These are set out in Table 4.

In 2007, ALF stated that its priorities for action and government funding were to increase access to pulmonary rehabilitation, improve COPD diagnosis through enhanced access to spirometry testing, ensure equity of access to home oxygen, secure direct funding for epidemiological research, improve COPD diagnosis through increased community awareness, and increase funding to enhance self-management strategies for COPD patients. ${ }^{23}$ In 2009, ALF management, in response to our request to prioritize the 19 interventions considered by the PR coordinators (see above), nominated the following interventions in descending order of priority:

1. Develop a government service framework for COPD;

2. Target awareness campaigns in key geographical areas with high rates of COPD and low socioeconomic status;

3. Investigate reasons for low use of PR programs and identify ideal ratios of programs to populations;

4. Increase numbers of pulmonary rehab programs and secure increased support for existing PR programs;

5. Encourage the use of spirometry in screening by general practitioners; and

6. Intervene to improve health professionals' attitudes toward patients with COPD.

\section{Discussion}

\section{Trends in COPD mortality rates}

A review of the research evidence makes it clear that mortality from COPD in men has been halved from 1980 to 2007,

Table $4 \mathrm{~A}$ framework for communicating appropriate messages about COPD to different target groups. Copyright (C) 200I, Australian Lung Foundation. Reproduced with permission from lungnet.com.au [website on the Internet]. Australian Lung Foundation. 200I. Available from: http://www.lungnet.com.au/ home/default.htm. Accessed November II, 2008. ${ }^{34}$

\begin{tabular}{ll}
\hline Target groups & Message \\
\hline $\begin{array}{l}\text { People with COPD } \\
\text { People unaware they have COPD }\end{array}$ & $\begin{array}{l}\text { "Something can be done" } \\
\text { "Take control now before } \\
\text { it becomes a problem" }\end{array}$ \\
$\begin{array}{l}\text { General public (candidates for COPD) } \\
\text { "Smoking causes COPD" } \\
\text { "Things have changed } \\
\text { Government }\end{array}$ & $\begin{array}{l}\text { in COPD" } \\
\text { "COPD is a major problem" }\end{array}$ \\
\hline
\end{tabular}

Abbreviation: COPD, chronic obstructive pulmonary disease. and that the prevalence of the disease has also considerably declined. This has been accompanied by a very large reduction in smoking rates in men and a lesser reduction in smoking rates for women. These can be attributed in substantial part to the very active smoking cessation programs in all Australian states and territories from 2000 to 2010.

This trend in mortality appears inconsistent with the projection by Murray and Lopez from the Global Burden of Disease (GBD) study, which, using a risk factor model, predicted that COPD would become the third-leading cause of death by $2020 .{ }^{1}$ The application of another risk factor model to COPD in the Netherlands by Feenstra et al also concluded that there will be a $75 \%$ increase in disabilityadjusted life years lost between 1994 and 2015. This was deemed to be largely due to an aging in the population and past smoking behavior, with changes in smoking rates having only a small effect..$^{25}$

In contrast, however, Lopez et al noted that the risk factor model used in the GBD study provided a relatively poor fit for the data. They used instead an extrapolation model, specifically a Bayesian age-period-cohort model. ${ }^{26}$ In conducting this analysis, they noted that deaths from COPD in males and younger females have declined in England and Wales in recent years (with the decline starting at different periods in different age groups), but have been increasing in older females. This UK trend is similar to the Australian trend described earlier.

The authors of the Lopez study tested the model by making short-term forward predictions for the period from 1990 to 1999 using longer-term data and comparing these with routinely available mortality data for the same period. They obtained estimates of median totals for COPD deaths within $9 \%$ for male and $5 \%$ for female observed rates. Projections for 2000-2009 suggested a median fall in death rates for males of $24 \%$ by 2009 on a 1999 baseline and a corresponding $2 \%$ rise for females, albeit with wide confidence intervals associated with marked year-to-year fluctuations in rates. While the authors counsel caution in the ability of any models to make longer-term predictions, it is clear that they were implicitly drawing attention to limitations in the GBD model and its prediction that COPD mortality rates will rise to very high levels in the future.

\section{Trends in COPD management}

New local evidence-based guidelines based on the GOLD guidelines have also been published. Several governments and ALF have provided support for these guidelines, as well as support for self-management and coordinated care. 
It is difficult to precisely assess the contribution of these activities in increasing conformity with the COPD-X Plan. This is because the Matheson et al study, conducted before publication of the COPD-X Plan, and the Ta and George study, conducted after its publication, involve very different patient populations. ${ }^{8,22}$ Nevertheless, it is apparent that, while some progress seems to have occurred, both studies report considerable departures from evidence-based practice. Ta and George believe, however, that there may have been some increase in influenza immunization rates across the relevant study period. This lack of obvious progress contrasts with the clear progress that has been made in the smoking-cessation area. A replication or extension of the Matheson et al study would enable judgments about changes in practices highlighted in the COPD-X Plan during the last five years.

\section{Community and professional awareness of COPD}

A common priority for patients, PR coordinators, and ALF was that there needed to be greater awareness of COPD in the Australian community generally and - more specifically - in the general practitioner and health professional communities. This, however, needed to be accompanied by a more positive orientation toward people with COPD. This was needed to overcome the stigma of what many saw as a self-inflicted disease. It is easy to imagine that this stigma can easily compound professional attitudes of therapeutic nihilism toward the disease. Progress in reducing disease levels and smoking rates gives convincing illustrations that this therapeutic nihilism is unjustified.

ALF sponsored a community awareness media campaign about COPD in Toowoomba, Queensland, in August 2007. ${ }^{27}$ It included print, radio, and television advertisements and aimed to improve early detection. Printed leaflets and displays in general practitioner waiting rooms, pharmacies, community health centers, and other outlets were used to increase awareness. This occurred alongside radio and television and printed media campaigns being run in a concentrated time period over one month. Similar campaigns aimed at raising awareness in both Norway and the United States have reported success in raising awareness in COPD in their respective populations. ${ }^{28,29} \mathrm{~A}$ more recent campaign (Show Us Your Lungs, 2011) was instigated by ALF, but evaluation of the effectiveness of the campaign has yet to be published..$^{30}$

Awareness campaigns are also needed to address stigmas, as well as low awareness. A modification of the message of the Global Lung Cancer Coalition ("No one deserves lung cancer"), to "No one deserves COPD" could be considered. ${ }^{31}$

Other priorities nominated by stakeholders included needed changes in general practice, such as earlier detection with spirometry in general practice, better smoking cessation programs, and an expanded (and cheaper) range of aids to support patients. A recent study by Abramson et al was unable, however, to demonstrate that thrice-monthly spirometry and regular medical reviews by general practitioners were associated with any significant improvement in quality of life or other health outcomes for patients with asthma and/or COPD. ${ }^{32}$

Some nominated the need for the expansion of pulmonary rehabilitation programs (alongside a study of the reasons for their current low use). Some also spoke of the need for a program similar to the National Service Framework (renamed the National Clinical Strategy for COPD), which exists in the UK. This specified the minimum standards of treatment and care that people with COPD can expect in their locality, and aims to facilitate people having access to the same standard of care regardless of where they live. ${ }^{33}$

\section{Limitations of the research}

While this informant approach was adequate for the purposes of this study, additional expressions of opinion from a more representative group of COPD sufferers and health professionals would have provided further insight. The insights from Australian experience do not, of course, necessarily translate to other countries with different health systems. In addition, the study of PR coordinators and COPD patients in patient support groups was based in Victoria, and may not be representative of the views involving these groups across Australia.

\section{Conclusion}

A reduction in mortality rates and the prevalence of COPD, alongside reductions in smoking cessation rates, contrast with the more limited progress that has been made in the adoption of other aspects of evidence-based practice for COPD in Australia. It provides further evidence that nihilism in relation to COPD is not justified. This could form the focus for media campaigns aimed at this and other aspects of community awareness and attitudes in relation to COPD. The recent passage through the Australian Parliament of required plain packaging of cigarettes is further illustration that progress can be expected. 


\section{Disclosures}

The stakeholder consultations were funded by the Department of Human Services, Victoria. However, the work and conclusions described are the responsibility of the authors.

\section{References}

1. Murray CJ, Lopez AD. The Global Burden of Disease. Boston, MA: Harvard School of Public Health, Harvard University Press; 1996.

2. goldcopd.org [website on the Internet]. Global Initiative for Chronic Obstructive Lung Disease. 2012. Available from: http://www.goldcopd. org/guidelines-global-strategy-for-diagnosis-management.html. Accessed January 17, 2012.

3. Vermeire P. The burden of chronic obstructive pulmonary disease. Respir Med. 2002;96 Suppl C:S3-S10.

4. AIHW. Australia's Health 2010. Australia's health series no. 12. Cat. no. AUS 122. Canberra, Australia: AIHW; 2010.

5. Begg S, Vos T, Barker B, Stevenson C, Stanley L, Lopez AD. The Burden of Disease and Injury in Australia 2003. PHE 82. Canberra, Australia: AIHW; 2007.

6. Australian Bureau of Statistics. ABS Survey of Disability Ageing and Carers (SDAC). Canberra, Australia: Australian Bureau of Statistics; 2003.

7. Australian Bureau of Statistics. 4364.0 - National Health Survey: Summary of Results, 2007-2008 (Reissue). Canberra, Australia: Australian Bureau of Statistics; 2009.

8. Matheson MC, Abeysena C, Raven JM, et al. How have we been managing chronic obstructive pulmonary disease in Australia? Intern Med J. 2006;36(2):92-99.

9. Buist AS, McBurnie MA, Vollmer WM, et al. International variation in the prevalence of COPD (the BOLD Study): a population-based prevalence study. Lancet. 2007;370(9589):741-750.

10. Toelle BG, Xuan W, Bird T, et al. COPD in the Australian Burden of Lung Disease (BOLD) Study. Am J Respir Crit Care Med. 2011;183:A1733.

11. Access Economics. Economic Impact of COPD and Cost Effective Solutions. Canberra, Australia: Access Economics Ptd Ltd; 2008.

12. Ansari Z, Dunt D, Dharmage SC. Variations in hospitalizations for chronic obstructive pulmonary disease in rural and urban Victoria, Australia. Respirology. 2007;12:874-880.

13. AIHW. Australian Hospital Statistics 2005-2006. Health services series no. 30. Cat. no. HSE 50. Canberra, Australia: AIHW; 2007.

14. Scollo MM, Winstanley MH, editors. Tobacco in Australia: Facts and Issues, 3rd ed. Melbourne, Australia: Cancer Council Victoria; 2008.

15. Ministerial Council on Drug Strategy. National Tobacco Strategy, 2004-2009: The Strategy. Canberra, Australia: Commonwealth of Australia; 2004.

16. McKenzie DK, Frith PA, Burdon JGW, Town GI. The COPDX Plan: Australian and New Zealand Guidelines for the management of Chronic Obstructive Pulmonary Disease 2003. Med J Aust. 2003; 178(Suppl 6):S1-S40.

17. copdx.org.au [website on the Internet]. The COPDX Plan; 2011. Available from: http://www.copdx.org.au/index.php. Accessed January 16, 2012.

18. National Health Priority Action Council. Chronic Disease Strategy. Canberra, Australia: Australian Government Department of Health and Ageing; 2006.

International Journal of COPD

\section{Publish your work in this journal}

The International Journal of COPD is an international, peer-reviewed journal of therapeutics and pharmacology focusing on concise rapid reporting of clinical studies and reviews in COPD. Special focus is given to the pathophysiological processes underlying the disease, intervention programs, patient focused education, and self management protocols.
19. healthnetworks.health.wa.gov.au [website on the Internet]. Government of Western Australia Department of Health; undated. Available from: http://www.healthnetworks.health.wa.gov.au/abhi/priority/index.cfm. Accessed October 28, 2011.

20. health.gov.au [website on the Internet]. Australian Government Department of Health and Ageing; undated. Available from: http://www. health.gov.au/internet/main/publishing.nsf/Content/mbsprimarycarechronicdiseasemanagement. Accessed August 27, 2011.

21. quit.org.au [website on the Internet]. Quitline; undated. Available from: http://www.quit.org.au. Accessed October 28, 2011.

22. Ta M, George J. Management of chronic obstructive pulmonary disease in Australia after the publication of national guidelines. Intern Med J. 2011;41(3):263-270.

23. lungfoundation.com.au [website on the Internet]. Australian Lung Foundation; 2008. Available from: http://www.lungfoundation.com. au/our-initiatives/copd-national-program/copd-advocacy/submissionto-the-national-health-a-hospital-reform-commission. Accessed November 1, 2011.

24. lungfoundation.com.au [website on the Internet]. StollzNow Research and Insights Advisory. 2007. Available from: http://www. lungfoundation.com.au/lung-information/publications/pulmonaryrehabilitation-survey-results-2007. Accessed November 2, 2011.

25. Feenstra TL, van Genugten ML, Hoogenveen RT, Wouters EF, Ruttenvan Molken MP. The impact of aging and smoking on the future burden of chronic obstructive pulmonary disease. Am J Respir Crit Care Med. 2001;164(4):590-596.

26. Lopez AD, Shibuya K, Rao C, et al. Chronic obstructive pulmonary disease: current burden and future projections. Eur Respir J. 2006;27(2):397-412.

27. thoracic.org.au [website on the Internet]. Thoracic Society of Australia and New Zealand. 2007. Available from: www.thoracic.org.au/ imagesDB/wysiwyg/tsn_200709.pdf. Accessed February 13, 2012.

28. Gulsvik A, Myrseth SE, Henrichsen SH, Humerfelt S, Omenaas E. Increased awareness of COPD in the Norwegian population. Clin Res J. 2007;1(2):118-119.

29. nih.gov [website on the Internet]. National Institute of Health. 2010. Available from http://www.nih.gov/news/health/nov2010/nhlbi-09a. htm. Accessed November 12, 2011.

30. lungfoundation.com.au [website on the Internet]. Australian Lung Foundation. 2011. Available from: http://www.lungfoundation.com. au/showusyourlungs. Accessed February 13, 2012.

31. lungcancercoalition.org [website on the Internet]. Global Lung Cancer Coalition. 2011. Available from http://www.lungcancercoalition.org/ en/global-perceptions-lung-cancer-0. Accessed November 2, 2011.

32. Abramson M, Schattner RL, Sulaiman ND, et al. Do spirometry and regular follow-up improve health outcomes in general practice patients with asthma or COPD? A cluster randomised controlled trial. Med J Aust. 2010;193(2):104-109.

33. lunguk.org [website on the Internet]. British Lung Foundation; undated. Available from: http://www.lunguk.org/campaigns/campaigns/what_ is_the_national_strategy_for_copd. Accessed November 2, 2011.

34. lungnet.com.au [website on the Internet]. Australian Lung Foundation. 2001. Available from: http://www.lungnet.com.au/home/default.htm. Accessed November 11, 2008.

This journal is indexed on PubMed Central, MedLine and CAS. The manuscript management system is completely online and includes a very quick and fair peer-review system, which is all easy to use. Visit http://www.dovepress.com/testimonials.php to read real quotes from published authors.

\section{Dovepress}

